\title{
PEMETAAN DAN KLASIFIKASI SEDIMEN DENGAN INSTRUMEN SIDE SCAN SONAR DI PERAIRAN BALONGAN, INDRAMAYU-JAWA BARAT
}

\author{
(Mapping and Sediment Classification using Side Scan Sonar Instrument at Balongan, \\ Indramayu - West Java)
}

Dwi Charnila ${ }^{1}$, Henry M. Manik ${ }^{2}$

\begin{abstract}
Based on the detection results of seafloor using side scan sonar in imaging objects of seafloor is able to create many image variants which is used for objects of seafloor imaging, beside it is able to give any information of seashore development. The purposes of this research are visualization or seafloor mapping and sediment classification or object of seabed qualitatively, So its possible to know the condition of seafloor. Interpretation and side scan sonar acoustic data classification is done qualitatively using Sonar Pro software to see the geometric form and unique of an object. Sampling of sediment is done at six track of transect which is space among transects $0.5 \mathrm{~km}$. Every transects has three sediment sample stations and total amount is eighteen samples of sediment. Based on the results of seafloor mapping at Balongan there are sediment disposal, trenching and sediment dredge, beside there are objects such as box, mooring, piece of pipe, rope, pole.
\end{abstract}

Keywords: side scan sonar, sediment classification, object of seafloor, SonarPro

\begin{abstract}
ABSTRAK
Berdasarkan hasil deteksi dasar laut menggunakan side scan sonar dalam pencitraan benda-benda di dasar laut dapat menghasilkan berbagai variasi gambar yang digunakan untuk pencitraan objek-objek dasar laut, selain itu dapat memberikan informasi dalam pengembangan wilayah pantai. Tujuan dari penelitian ini adalah visualisasi atau pemetaan dasar perairan dan klasifikasi sedimen atau objek di dasar laut secara kualitatif, sehingga dapat diketahui keadaan dasar laut. Interpretasi dan klasifikasi data akustik side scan sonar dilakukan secara kualitatif dengan menggunakan software Sonar Pro untuk melihat bentuk geometris dan keunikan dari suatu objek. Pengambilan contoh sedimen dilakukan pada 6 jalur transek dengan jarak antar transek $0.5 \mathrm{~km}$. Setiap transek terdapat 3 buah stasiun sampel sedimen dan jumlah total adalah 18 sampel sedimen. Berdasarkan hasil pemetaan dasar laut daerah Balongan terdapat buangan sedimen, paritan dan kerukan sedimen, selain itu terdapat objek seperti box, mooring, potongan pipa, tali, pole.
\end{abstract}

Kata kunci: side scan sonar, klasifikasi sedimen, objek dasar laut, SonarPro

\section{PENDAHUluan}

Side scan sonar dalam pencitraan benda-benda di dasar laut dapat menghasilkan berbagai variasi gambar. Metode visualisasi digunakan untuk membantu interpretasi untuk mengamati objek di dasar laut. Gambar yang dihasilkan dari hasil perekaman side scan sonar memberikan suatu gambar (image) dari dasar laut yang beresolusi tinggi serta memberikan informasi tentang tekstur sedimen dan struktur bentuk dasar laut.

Contoh rekaman side scan ditunjukkan pada Gambar 1. Pada Gambar ini dapat dibedakan berbagai jenis objek di dasar laut termasuk pasir, endapan sedimen, karang dan lain-lain.
Semakin kuat backscatter maka akan semakin gelap rekaman tersebut.

Dual frekuensi digital dalam perangkat side scan sonar memiliki gambar dasar laut dengan resolusi yang tinggi dan menghasilkan gambar yang hampir realistik dari dasar laut. Beberapa sapuan dapat menghasilkan mosaik, geologi dan fitur sedimentologis yang mudah dikenali dan diinterpretasi secara kualitatif sehingga dapat memberikan informasi tentang dinamika dasar laut (Kenny et al, 2003). Penelitian ini dilakukan untuk visualisasi atau pemetaan dasar perairan dan klasifikasi sedimen atau objek di dasar laut di Perairan Balongan, Indramayu Jawa Barat.

\footnotetext{
${ }^{I}$ Alumni Departemen Ilmu dan Teknologi Kelautan FPIK IPB

${ }^{2}$ Staf pengajar Departemen Ilmu dan Teknologi Kelautan, FPIK-IPB
} 


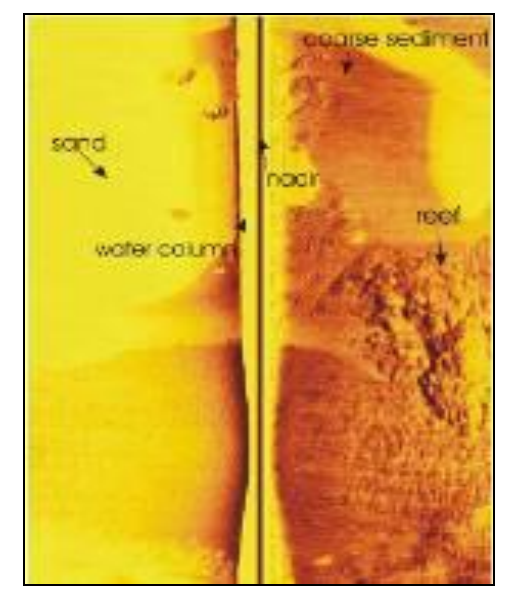

Gambar 1. Rekaman side scan sonar, nadir merupakan pengganti dari trek kapal (McCauley dan Siwabessy, 1987)

\section{METODE PENELITIAN}

\subsection{Pengambilan Data}

Penelitian ini merupakan salah satu rangkaian kegiatan survei dalam pengembangan pembangunan pelabuhan dalam perencanaan perpanjangan pemecah gelombang yang dilakukan oleh Pusat Penelitian dan Pengembangan Geologi Kelautan (P3GL) di daerah Balongan, Kabupaten Indramayu, Jawa Barat. Penelitian ini dilakukan di daerah $\mathrm{Ba}-$ longan, Desa Sukareja, Kabupaten Indramayu, Jawa Barat. Daerah ini terletak pada koordinat $6^{\circ} 21^{\prime} 48$ "LS - 6 ${ }^{\circ} 22^{\prime} 54$ "LS dan $108^{\circ} 24^{\prime} 18 " \mathrm{BT}-108^{\circ} 25^{\prime}$ 49"BT dapat ditunjukan pada Gambar 2.
Pengambilan data lapangan menggunakan side scan sonar Klein System 3000, alat ini dioperasikan dengan menggunakan seperangkat komputer untuk merekam data secara real time, dan Global Positioning System (GPS) yang terpasang di kapal untuk mengetahui posisi lintang (latitude) dan bujur (longitude). Peranan GPS sangat dibutuhkan untuk mengetahui lokasi dalam penentuan wilayah pada saat pengambilan data dilakukan. Pengambilan data akustik manggunakan side scan sonar dilakukan dengan frekuensi $500 \mathrm{kHz}$ dan $100 \mathrm{kHz}$ dalam memetakan gambaran lateral dan membantu mengklasifikasikan dasar suatu perairan. Dalam pengolahan data dilakukan dengan frekuensi $500 \mathrm{kHz}$ karena dapat menghasilkan gambar yang lebih detail.

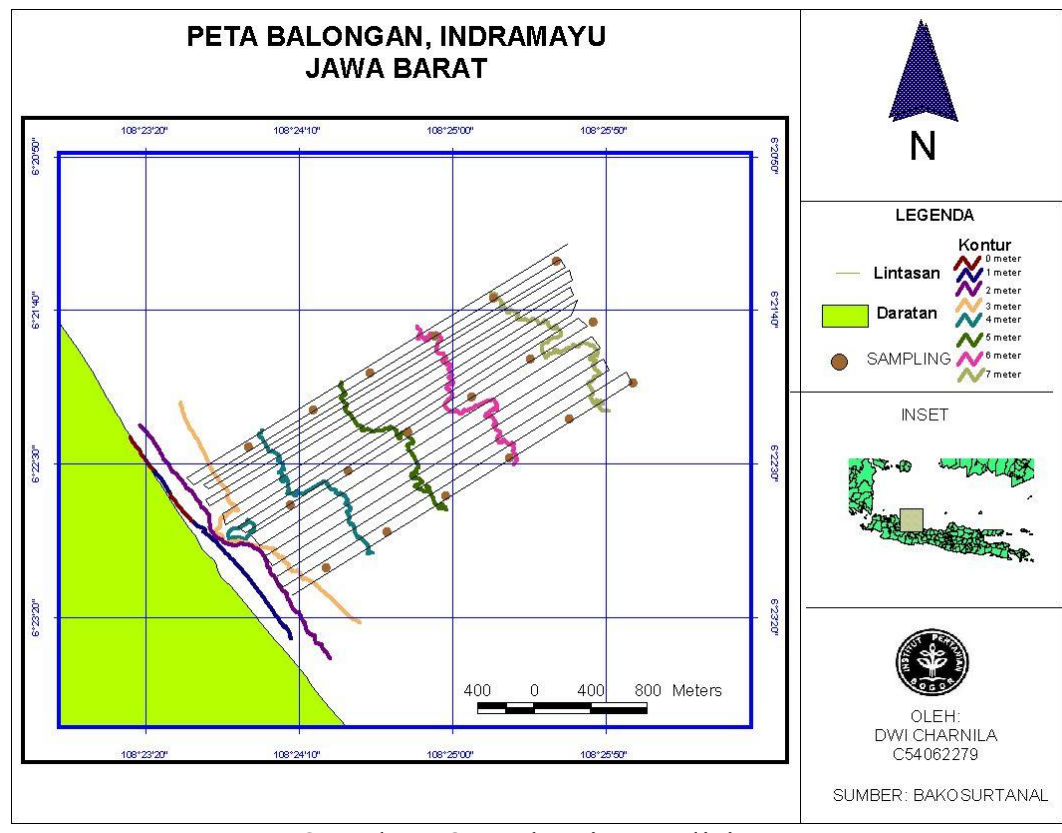

Gambar 2. Lokasi Penelitian 
Tabel 1. Spesifikasi Side scan sonar Klein 3000

\begin{tabular}{|l|l|}
\hline Towfish Specificcations \\
\hline Frequencies & $100 \mathrm{kHz}$ dan $500 \mathrm{kHz}$ \\
\hline Range Scales & 15 settings - 25 to 1,000 meters \\
\hline Maximum Range & 600 meters @ $100 \mathrm{kHz} ; 150$ meters @ $500 \mathrm{kHz}$ \\
\hline Depth Rating & 1,500 meters \\
\hline Construction & Stainless Steel \\
\hline Size & $122 \mathrm{~cm}$ long, $8.9 \mathrm{~cm}$ diameter \\
\hline Weight & $29 \mathrm{~kg}$ in air \\
\hline Standard sensors & Roll, pitch, heading \\
\hline
\end{tabular}

Pengolahan dan analisis data dilakukan pada bulan Februari-Juli 2010 di laboratorium akustik kelautan Fakultas Perikanan dan Ilmu Kelautan, Departemen Ilmu dan Teknologi Kelautan, Institut Pertanian Bogor dan P3GL di Bandung.

Pengambilan sampel sedimen dilakukan dengan menggunakan sedimen grab sampler, dengan memiliki luas bukaan sebesar $15 \times 15 \mathrm{~cm}^{2}$ kemudian sampel di analisa di laboratorium. Pengambilan sedimen dilakukan 6 jalur transek dengan jarak antar transek $0.5 \mathrm{~km}$. Setiap transek terdapat 3 buah stasiun sampel sedimen dengan keseluruhan 18 sampel sedimen.

\subsection{Pengolahan Data}

Pengolahan data diawali dengan menggunakan software Sonar Pro dengan format data hasil rekaman dalam bentuk *sdf, dilakukan secara kualitatif dengan melihat bentuk geometris dari suatu objek yang akan diklasifikasikan secara alami maupun buatan. Interpretasi dan klasifikasi data side scan sonar dilakukan secara kualitatif.

Selain itu dilakukan pengolahan mosaik data side scan sonar dengan menggabungkan semua data di sepanjang track kapal yang dilalui oleh instrumen tersebut. Dalam pengolahan data digunakan perangkat lunak Sonarweb untuk menghasikan suatu mosaik, yang merupakan penggabungan dari dua atau lebih lintasan survei yang berdampingan dan memiliki overlapping $100 \%$.

Prinsip side scan sonar adalah saat sinyal ditransmisikan akan merambat dalam air ditunjukan pada gambar 3, transduser sonar dapat menerima noise dan echo. Echo dasar laut yang menghasilkan pantulan pertama sangat kuat sebagai kekuatan backscatter maksimal dan kerugian transmisi yang minimal. Efek dalam pembentukan bayangan dari dasar laut dapat terjadi dan akan mencegah terjadinya backscattering dari dasar perairan yang terhalang bayangan tersebut. Echo yang dihasilkan biasanya sangat rendah dan akan menghasilkan gambar sonar sama dengan bayangan obyek, analisis ini akan memberikan perkiraan ukuran dan bentuk objek (McCauley dan Siwabessy, 1987).

Pancaran sinyal suara yang dipancarkan oleh transduser yang berinteraksi dengan dasar laut pada sudut miring, sejumlah energi terpancar dari transduser dan sebagian dipantulkan kembali ke transduser oleh objek di dasar laut. Energi yang dipantulkan kembali ini dikenal sebagai backscatter akustik (McCauley, R.D and J.P. Siwabessey. 1987).

Pengolahan data side scan sonar secara post processing yaitu pengolahan citra side scan dengan cara interpretasi. Suatu citra side scan sonar memiliki berbagai informasi yang tersimpan di dalamnya. Gambar 4 menunjukan interpretasi terhadap citra side scan sonar dapat dilakukan secara kualitatif untuk mendapatkan perkiraan sifat-sifat fisik dari material dan penentuan bentuk objek atau secara kuantitatif untuk mendefinisikan hubungan antara posisi kapal, posisi towfish dan posisi objek. 


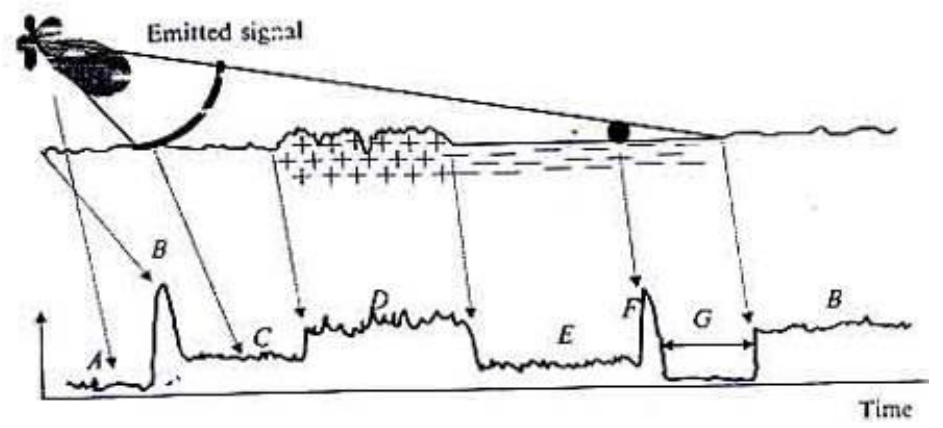

Gambar 3. (A) Noise dan reverberasi dalam kolom air, (B) Echo pertama dari dasar perairan, (C) Area pasir, (D) Batuan, (E) Lumpur (F) pantulan dari target dan (G) Bayangan dari target (Lurton, 2002)

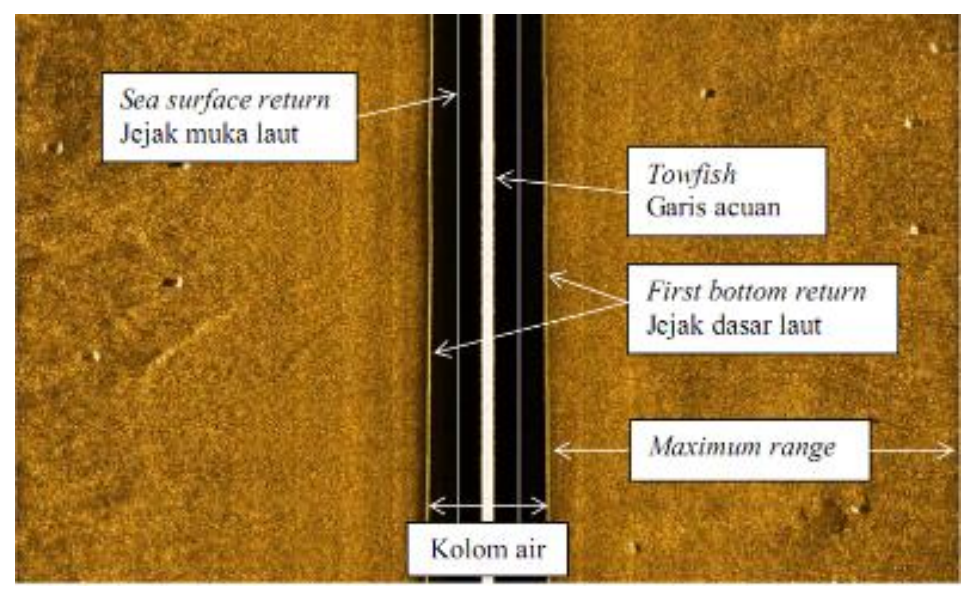

Gambar 4. Citra side scan sonar (Mahyuddin, 2008)

Selain itu Pembuatan layer pada set data, overlay dilakukan menggunakan software arcGis, dengan menggunakan arcsceen. Nilai kedalaman dan jenis sedimen yang akan dipetakan akan diinterpolasi. Hasil interpolasi akan disatukan menjadi layer yang berupa data kedalaman, mosaik side scan sonar dan titik sampel sedimen. Data set overlay ini digunakan sebagai data penunjang dalam pengolahan side scan sonar.

\section{HASIL DAN PEMBAHASAN}

\subsection{Visualisasi Objek Buatan}

Hasil yang ditampilkan pada pengolahan side scan sonar menunjukan bahwa Pola pengembalian pulsa dan bayangan objek yang terlihat dapat mengungkapkan bentuk objek di dasar laut. Pada objek pole terlihat dengan berbentuk bulat dan membentuk suatu bayangan dengan memberikan kontras dengan permukaan substrat disekitarnya. ditunjukan pada Gambar 5 .

Bayangan yang dipengaruhi energi hambur balik yang memiliki hubungan geometris antara transduser dan target yang dapat menghasilkan suatu bayangan tertentu contohnya objek yang berbentuk Box.

Jangkar Single Point Mooring (SPM) yang digunakan untuk tambat labuh kapal kapal tanker karena adanya proses sedimentasi sehingga mengakibatkan pendangkalan di daerah ini ditunjukan pada Gambar 7. 

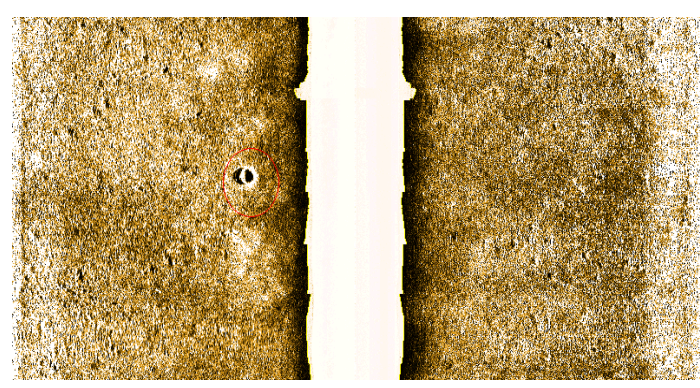

Gambar 5. Pole
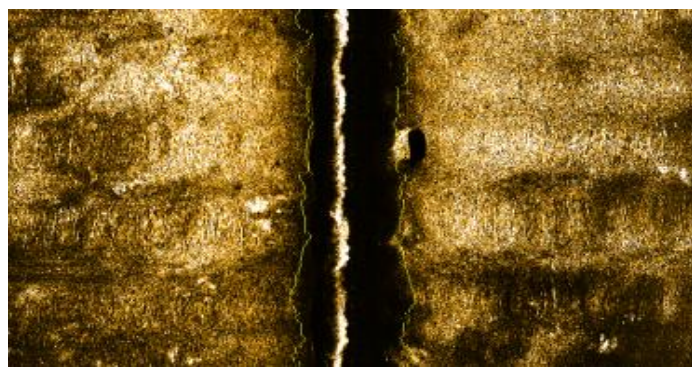

Gambar 6. Box

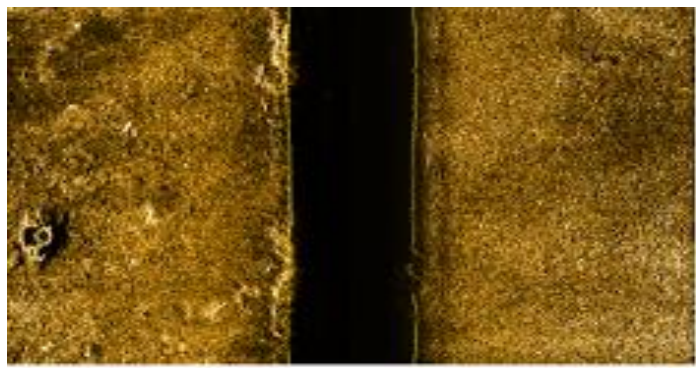

Gambar 7. Jangkar Single Point Mooring

Material objek buatan pada umumnya memiliki backscatter yang efisien dalam merefleksikan pulsa akustik. Semakin kuat backscatter maka akan semakin gelap gambar yang terbentuk. Efek dalam pembentukan bayangan dari dasar laut cukup besar akan menghalangi dari sudut yang ditransmisikan dan mencegah backscattering dari dasar perairan dan echo yang dihasilkan sangat rendah akan menghasilkan gambar sonar sama dengan bayangan obyek, analisis ini akan memberikan perkiraan ukuran dan bentuk objek.

\subsection{Klasifikasi sedimen}

Berbagai bentuk sedimen secara alami dan buatan telah dihasilkan. Terdapat bentuk sedimen buatan (Gambar 8a dan 8b) seperti kerukan dan buangan sedimen. Sedimen alami berupa pasir dan lumpur yang ditunjukan oleh Gambar (Gambar 9a dan 9b). Kerukan sedimen terlihat permukaan substrat dengan citra yang dihasilkan membentuk gelombang seperti hasil kerukan. Begitu juga dengan buangan yang merupakan suatu endapan atau timbunan hasil kerukan sedimen yang menumpuk yang membentuk suatu bayangan pada rekaman side scan sonar.

Dalam pencitraan side scan yang memiliki amplitudo hambur balik tinggi pada umumnya diwakili oleh gambaran yang lebih gelap pada rekaman, sedangkan nilai hambur balik yang rendah ditujukan lebih terang. Secara umum, daerah backscatter yang tinggi berhubungan dengan sedimen yang kasar dan hambur balik yang relatif rendah memiliki sedimen yang lebih halus. Endapan permukaan sedimen dipengaruhi banyak faktor yaitu ukuran butir, skala kekasaran permukaan sedimen dan variasi kemiringan yang signifikan dapat menjadi peran penting dalam respon akustik (Urick, 1983 dalam Ehrhold et al, 2006).

Substrat berlumpur terlihat dari citra side scan memiliki permukaan yang halus. $\mathrm{Hal}$ ini berbeda dengan pasir yang terdapat riak yang bergelombang yang memiliki permukaan yang lebih kasar. 


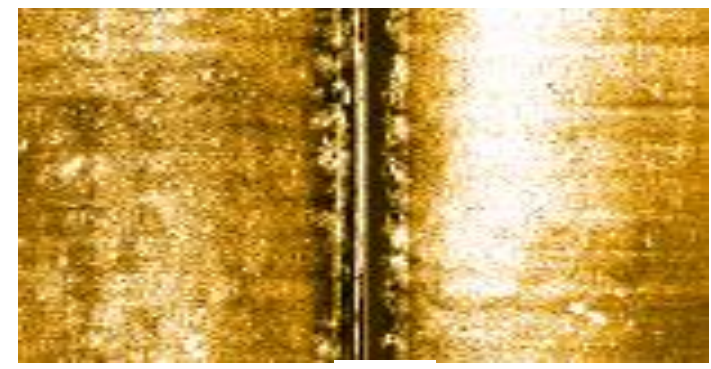

(a)

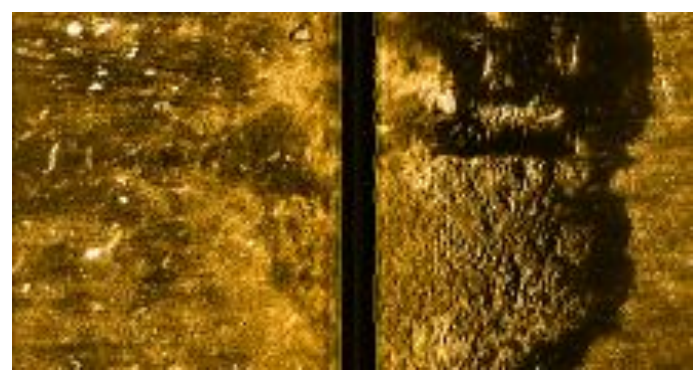

(b)

Gambar 8. Klasifikasi sedimen buatan (a) Kerukan sedimen dan (b) Buangan Sedimen

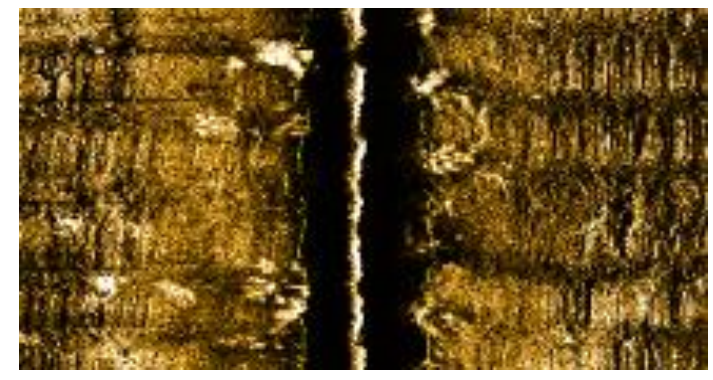

(a)

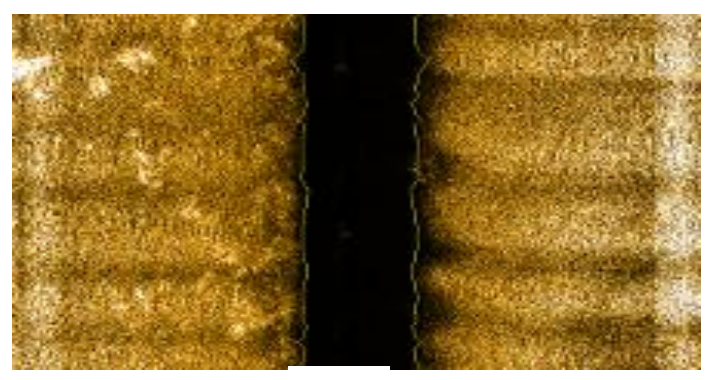

(b)

Gambar 9. Klasifikasi sedimen alami (a) Pasir dan (b) Lumpur

Side scan sonar menggunakan prinsip backscatter akustik dalam membedakan kenampakan bentuk dasar laut atau objek dasar laut. Permukaan lumpur halus dapat menghasilkan pulsa back-scatter yang lemah, berbeda dengan permukaan bertekstur yang lebih keras yaitu pasir, dapat memberikan pengembalian backscatter yang lebih kuat. Diketahui bahwa fenomena backscattering yang berhubungan dengan dasar laut memiliki hubungan dengan kekasaran (Gardner et al, 1991; Jackson et al, 1986, dalam Colliera dan Brown, 2005). Keka-saran permukaan dapat berhubungan langsung dengan ukuran butir atau faktorfaktor lain seperti struktur sedimen atau gelembung udara (Urgeles et al, 2002; Fonseca et al, 2002, dalam Colliera dan Brown, 2005).

\subsection{Mosaik side scan sonar dan set data overlay}

Hasil pemetaan dasar laut daerah Balongan menampakkan buangan sedimen, paritan dan kerukan sedimen, selain itu terdapat objek seperti box, mooring, potongan pipa, tali, pole (Gambar 10). Hasil analisis besar butir di perairan Balongan, Jawa Barat yang dilakukan oleh PPPGL memiliki sedimen dasar laut berupa lempung lanauan yang berada di bagian tengah alur, Hal ini terjadi karena adanya hasil kerukan karena proses sedimentasi sehingga mengakibatkan pendangkalan di daerah ini yang memiliki proporsi fraksi halus lebih banyak berupa lempung. Selain itu di bagian barat dan timur alur terdapat pasir lanauan dengan jumlah proporsi pasir yang lebih dominan. Klasifikasi ini berdasarkan sifat dari sedimen dapat dicirikan adanya berat fraksi antara butiran kasar dan halus. Penentuan asal sedimen dasar laut berdasarkan analisis besar butir dan mineral berat dapat dilakukan untuk mengetahui cara transportasi dan sedimentasi serta kandungan mineral berat yang terdapat pada sedimen pantai dan sedimen dasar laut di suatu perairan (Setiady, 2005).

Data mosaik side scan sonar diolah menggunakan sonarWeb dan dieksport dalam bentuk tiff yang diolah pada arcScene (Gambar 11). Gambaran mosaik dapat terlihat perbedaan sedimen pada daerah Balongan yaitu berupa lempung dan pasir lanauan. Data 3D batimetri menunjukan gambaran kedalaman di daerah Balongan berupa perairan yang dangkal. Kedalaman pada perairan ini berkisar antara $3-7 \mathrm{~m}$. Data set ini digunakan sebagai data penunjang dalam pengolahan side scan sonar. 


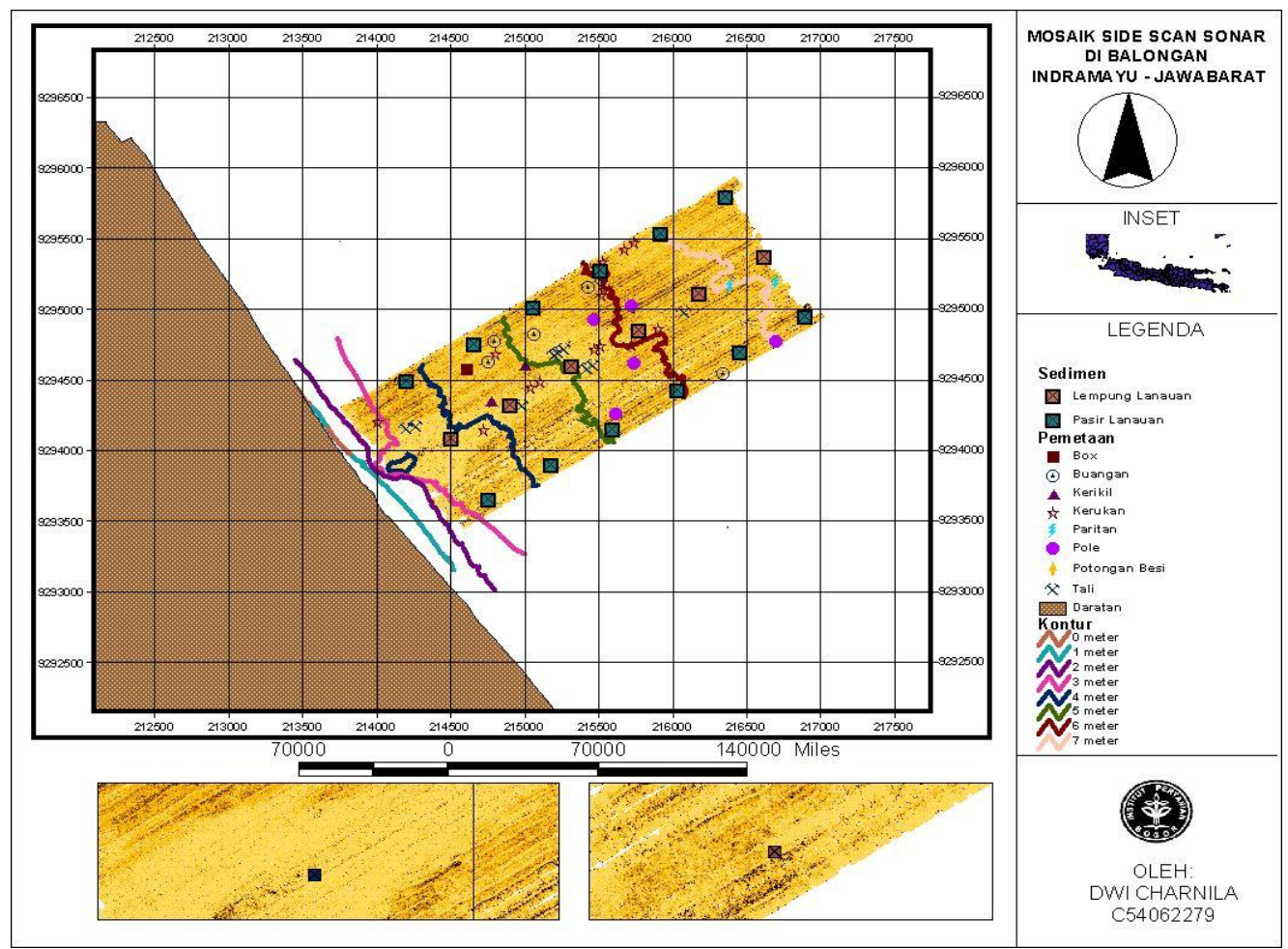

Gambar 10. Mosaik side scan sonar

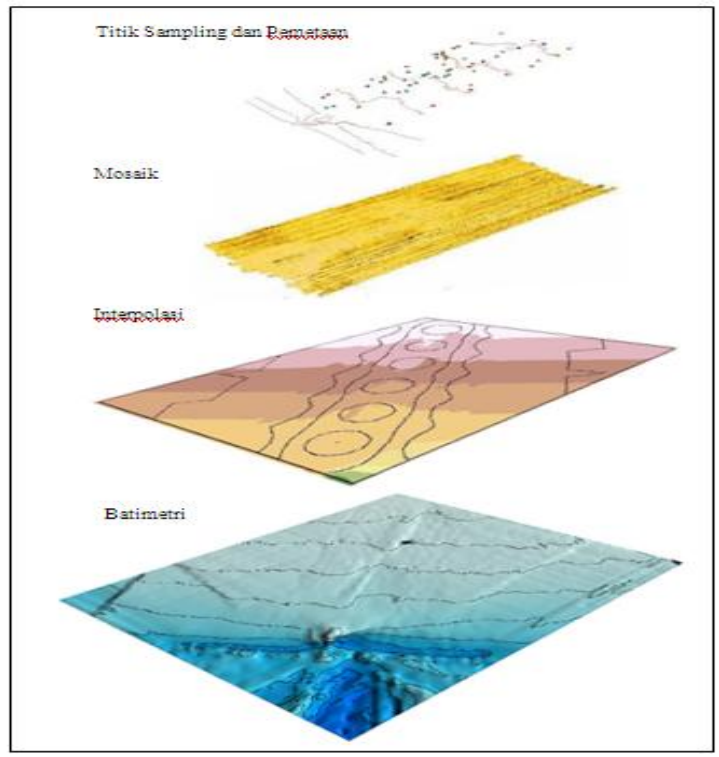

Gambar 11. Set data overlay

Batimetri dan tekstur sedimen memiliki saling keterkaitan, umumnya sedimen memiliki butiran lebih besar berupa kerikil atau pasir kasar akan diendapkan di sekitar dekat pantai, sedangkan sedimen yang berbutir lebih kecil yang lebih halus seperti lanau dan lempung diendapkan di laut. Begitu pula mineral karbonat atau gamping dien-dapkan lebih jauh lagi kearah laut (Dewi dan Darlan, 2008). Berbeda halnya dengan di Balongan yang memiliki sedimen yang lebih halus atau berbutir lebih kecil terdapat disekitar pantai. Hal ini disebabkan terjadinya proses sedimentasi dan terdapat masukan material - material dari sungai yang membawa partikel lebih halus. 


\section{KESIMPULAN}

Berdasarkan hasil dalam pencitraan side scan yang memiliki amplitudo hambur balik tinggi pada umumnya diwakili oleh gambaran yang lebih gelap pada rekaman. Material objek secara buatan pada umumnya memiliki backscatter yang efisien dalam merefleksikan pulsa akustik. Semakin kuat backscatter maka akan semakin kuat kontras gelap - terang gambar yang terbentuk. Pemetaan dasar laut daerah Balongan terdiri dari buangan sedimen, paritan dan kerukan sedimen, selain itu terdapat objek seperti box, mooring, potongan pipa, tali dan pole. Daerah Balongan memiliki sedimen dasar laut berupa lempung lanauan yang berada di bagian tengah alur. Selain itu di bagian barat dan timur alur terdapat pasir lanauan dengan jumlah proporsi pasir yang lebih dominan. Balongan yang memiliki sedimen yang lebih halus atau berbutir lebih kecil sebagian besar terdapat di-sekitar pantai.

\section{SARAN}

Klasifikasi sedimen menggunakan metode wavelet pada penelitian ini dapat digunakan untuk melihat karakter sinyal yang dihasilkan pada objek di permukaan dasar laut untuk verifikasi data diperlukan juga adanya data gambar video sebagai data penunjang dalam pengintepretasi dasar laut. Selain itu diperlukan dalam pengolahan data kuantitatif secara 3D berdasarkan nilai echo yang dihasilkan dalam klasifikasi sedimen dasar laut dan nilai Impedansi pada masing - masing objek.

\section{DAFTAR PUSTAKA}

Colliera, J. S dan C. J. Brown. 2005. Correlation of sidescan backscatter with grain size distribution of surficial seabed sediments. Marine Geology (214): 431-449.
Dewi, K. T. dan Y. Darlan. 2008. Partikel mikroskopis dasar laut nusantara. Badan Penelitian dan Pengembangan Energi dan Sumber Daya Mineral. Departemen Energi dan Sumber Daya Mineral.

Ehrhold, A., D. Hamon, dan B. Guillaumont. 2006. The REBENT monitorring network,a spatially integrated, acoustic approach to surveying nearshore acrobenthic habitats: application to the Bay of Concarneau (South Brittany, France). ICES Journal of Marine Science (63): 1604-1615.

Kenny, A. J., I. Cato, M. Desprez, G. Fader, R.T.E. Schüttenhelm, dan J. Side. 2003. An overview of seabedmapping technologies in the context of marine habitat classification. ICES Journal of Marine Science (60): 411418.

Mahyuddin, M. F. 2008. Skripsi, Penggunaan Perangkat Lunak Sonar Pro Untuk Pengolahan Data Side Scan Sonar. Program Studi Teknik Geode-si dan Geomatika Fakultas Ilmu dan Teknologi Kebumian. Institut Teknologi Bandung.

McCauley, R. D dan J. P. Siwabessy. 1987. Coastal Zone CRC- Coastal Water Habitat Mapping - Shallow Water Assessment Technologies. Centre for Marine Science and Technology (CMST). Curtin University. Perth.

Setiady, D. 2005. Penentuan Asal Sedimen Permukaan Dasar Laut Berdasarkan Analisis Besar Butir dan Mineral Berat. Kumpulan Abstrak Tesis. Teknik Geologi. Institut Teknologi Bandung. 